\title{
Designing and implementing a socioeconomic intervention to enhance TB control: operational evidence from the CRESIPT project in Peru
}

Tom Wingfield ${ }^{1,2,3^{*}}$, Delia Boccia ${ }^{1,4}$, Marco A. Tovar ${ }^{1,5}$, Doug Huff, ${ }^{1,6}$, Rosario Montoya ${ }^{1}$, James J. Lewis ${ }^{4}$, Robert H. Gilman ${ }^{7}$ and Carlton A. Evans ${ }^{1,2,5}$

\begin{abstract}
Background: Cash transfers are key interventions in the World Health Organisation's post-2015 global TB policy. However, evidence guiding TB-specific cash transfer implementation is limited. We designed, implemented and refined a novel TB-specific socioeconomic intervention that included cash transfers, which aimed to support TB prevention and cure in resource-constrained shantytowns in Lima, Peru for: the Community Randomized Evaluation of a Socioeconomic Intervention to Prevent TB (CRESIPT) project.

Methods: Newly-diagnosed TB patients from study-site healthposts were eligible to receive the intervention consisting of economic and social support. Economic support was provided to patient households through cash transfers on meeting the following conditions: screening for TB in household contacts and MDR TB in patients; adhering to TB treatment and chemoprophylaxis; and engaging with CRESIPT social support (household visits and community meetings).

To evaluate project acceptability, quantitative and qualitative feedback was collected using a mixed-methods approach during formative activities. Formative activities included consultations, focus group discussions and questionnaires conducted with the project team, project participants, civil society and stakeholders.

Results: Over 7 months, 135 randomly-selected patients and their 647 household contacts were recruited from 32 impoverished shantytown communities. Of 1299 potential cash transfers, 964 (74 \%) were achieved, 259 (19\%) were not achieved, and 76 (7\%) were yet to be achieved. Of those achieved, 885/964 (92\%) were achieved optimally and 79/964 (8 \%) sub-optimally.

Key project successes were identified during 135 formative activities and included: strong multi-sectorial collaboration; generation of new evidence for TB-specific cash transfer; and the project being perceived as patient-centred and empowering.

Challenges included: participant confidence being eroded through cash transfer delays, hidden account-charges and stigma; access to the initial bank-provider being limited; and conditions requiring participation of all TB-affected household members (e.g. community meetings) being hard to achieve.

(Continued on next page)
\end{abstract}

\footnotetext{
* Correspondence: tom.wingfield@ifhad.org

'Innovación Por la Salud Y Desarrollo (IPSYD), Asociación Benéfica PRISMA,

Lima, Peru

${ }^{2}$ Innovation For Health And Development (IFHAD), Infectious Diseases \&

Immunity, Imperial College London, and Wellcome Trust Imperial College

Centre for Global Health Research, London, UK

Full list of author information is available at the end of the article
}

\section{Ciomed Central}

(c) 2015 Wingfield et al. Open Access This article is distributed under the terms of the Creative Commons Attribution 4.0 International License (http://creativecommons.org/licenses/by/4.0/), which permits unrestricted use, distribution, and reproduction in any medium, provided you give appropriate credit to the original author(s) and the source, provide a link to the Creative Commons license, and indicate if changes were made. The Creative Commons Public Domain Dedication waiver (http://creativecommons.org/publicdomain/zero/1.0/) applies to the data made available in this article, unless otherwise stated. 
(Continued from previous page)

Refinements were made to improve project acceptability and future impact: the initial bank-provider was changed; conditional and unconditional cash transfers were combined; cash transfer sums were increased to a locally-appropriate, evidence-based amount; and cash transfer size varied according to patient household size to maximally reduce mitigation of TB-related costs and be more responsive to household needs.

Conclusions: A novel TB-specific socioeconomic intervention including conditional cash transfers has been designed, implemented, refined and is ready for impact assessment, including by the CRESIPT project. The lessons learnt during this research will inform policy-makers and decision-makers for future implementation of related interventions.

\section{Background}

Tuberculosis kills 5000 people per day [1], mostly in resource-constrained settings. TB has long been recognised as an illness inextricably linked with social deprivation and marginalisation [2, 3]. Poverty predisposes individuals to $\mathrm{TB}[4,5]$ and hidden costs associated with even free TB treatment can be catastrophic: exacerbating poverty [6], leading to adverse TB treatment outcome, increasing TB transmission and potentially worsening TB control [7]. Nevertheless, the global model for TB prevention, management and research has been principally focused on biomedical rather than socioeconomic approaches [8, 9]. There is a pressing need to expand the traditional TB control paradigm based on case finding and treatment in order to embrace more holistic approaches that encompass the wellbeing of people and households living with TB and communities affected by TB [10-15]. This vision has been formally acknowledged in the World Health Organisation's (WHO) post-2015 global End TB Strategy [16] which, for the first time in the modern era of TB control, explicitly identifies poverty reduction strategies, including universal health coverage and social protection, as key pillars of the future global response to TB $[16,17]$.

Social protection consists of policies and programs designed to reduce poverty and vulnerability by improving people's capacity to manage social and/or economic risks [18], and includes health insurance, food assistance, travel vouchers and cash transfers [19]. Cash transfers generally provide economic support to impoverished people with the aim of moving them out of extreme poverty and vulnerability whilst improving human capital [20-25]. Cash transfers are already used to modulate behaviour in HIV/AIDS [26, 27] and improve maternal health [28]. Mitigating poverty-related TB risk factors of TB-affected households using cash transfers may be a cost-effective investment from a societal perspective [29] because it may support TB treatment, improve TB prevention and cure, and potentially enhance TB control [30]. However, there is little operational evidence to guide implementation or evaluate the impact of TB-related socioeconomic support including cash transfer interventions [15, 19-21, 31-40].
For over a decade, our research group (www.ifhad.org) has worked with TB-affected households in the shantytowns of Callao, Peru. From 2007 to 2011, we conducted an assessment of Innovative Socioeconomic Interventions Against TB (ISIAT) [39]. The interventions had two dimensions: i) education, community mobilization and psychosocial support to increase uptake of TB care; and ii) food transfers, microcredit, microenterprise and vocational training to reduce poverty. This intervention increased preventive chemotherapy in household contacts and HIV testing and TB treatment completion in TB patients [39].

Building on the lessons learnt during the ISIAT project, we designed a larger 6-year research project called CRESIPT: a "Community Randomized Evaluation of a Socioeconomic Intervention to Prevent TB" to test for impact on TB control. This paper aims to describe the challenges of implementation, lessons learnt and refinement of this complex socioeconomic intervention to control TB. The paper focuses on set up of a TB-specific cash transfer scheme, and thus aims to provide research groups, NGOs, civil-society representatives, policy-makers, stake-holders and the wider $\mathrm{TB}$ community with an interim guidance document concerning the operational logistics of TBadapted socioeconomic interventions involving cash transfers in resource-constrained settings.

\section{Methods}

\section{Intervention objectives}

The CRESIPT project aims to evaluate a socioeconomic intervention to support prevention and cure of $\mathrm{TB}$ in TB-affected households and, ultimately, improve community TB control. The CRESIPT socioeconomic intervention was developed over 7 months in two contiguous suburbs of Peru's capital, Lima: Ventanilla, 15 peri-urban shantytown communities in which our research group has been recruiting patients to an on-going cohort study for over a decade; [39] and Callao, an area including 17 impoverished urban communities.

\section{Intervention planning}

The CRESIPT project was informed by our previous research [39], extensive expert consultation [19], and a 
systematic review [20] of cash transfer interventions published in 2011.

We built upon an a priori conceptual framework reflecting the postulated pathways through which the intervention could lead to improved TB control in the study site (Fig. 1). The intervention outputs related to shared CRESIPT project and Peruvian National TB program goals: i. screening for TB in household contacts and MDR-TB in TB patients; ii. adhering to TB treatment and chemoprophylaxis; and iii. engaging with CRESIPT social support activities. Thus, our intervention targeted defined outcomes along the TB causal pathway. In TB patients, we aimed to improve early diagnosis and treatment, provide support to increase adherence to and completion of treatment, and achieve sustained cured. Amongst household contacts living with these TB patients, we aimed to prevent TB.

The previous systematic review of cash transfer interventions was updated in 2014: Medline, Embase, Global Health and HMIC databases were searched from 1st January 2011 onwards using the term "Tuberculosis/ economics" [Mesh] OR "Tuberculosis, pulmonary/ economics" [Mesh] OR "Tuberculosis/prevention and control" [Mesh] AND "Economic support" OR "Cash transfers". This search found only one randomized controlled evaluation of economic support to improve tuberculosis treatment outcomes [41]. Other necessary and informative literature on economic interventions did not meet inclusion criteria for this systematic review because it either related specifically to HIV/ AIDS (such as the IMAGE study) [42] or was limited by having no control group or impact assessment $[17,43]$.
A consultation process was undertaken to inform the project and its scope: a total of 135 formative activities were conducted including multi-sectorial meetings, focus group discussion (FGDs), semi-structured interviews, evidence reviews and other expert consultations (Table 1 and Fig. 2).

Table 2 summarises the critical review of the available evidence that occurred during the planning process, and the manner in which this review subsequently informed the main operational design and implementation decisions relating to some of the main aspects of the cash transfer intervention, including: existing cash transfer schemes, conditionality and transfer size.

Thus the planning process involving previous research, extensive expert consultation and systematic reviews of cash transfer interventions led to the design of a novel socioeconomic intervention that aimed to be locally-appropriate, feasible and sustainable and consisted of:

- economic support: conditional cash transfers to reduce $\mathrm{TB}$ vulnerability, incentivise and enable care; and

- social support: household visits and participatory community meetings for information, mutual support, stigma reduction and empowerment.

The participatory community meetings, which are reported separately, consisted of an interactive educational workshop concerning issues surrounding TB and household finances, and a "TB Club" in which participants shared TB-related and other experiences in a support group format specifically adapted to the local setting.

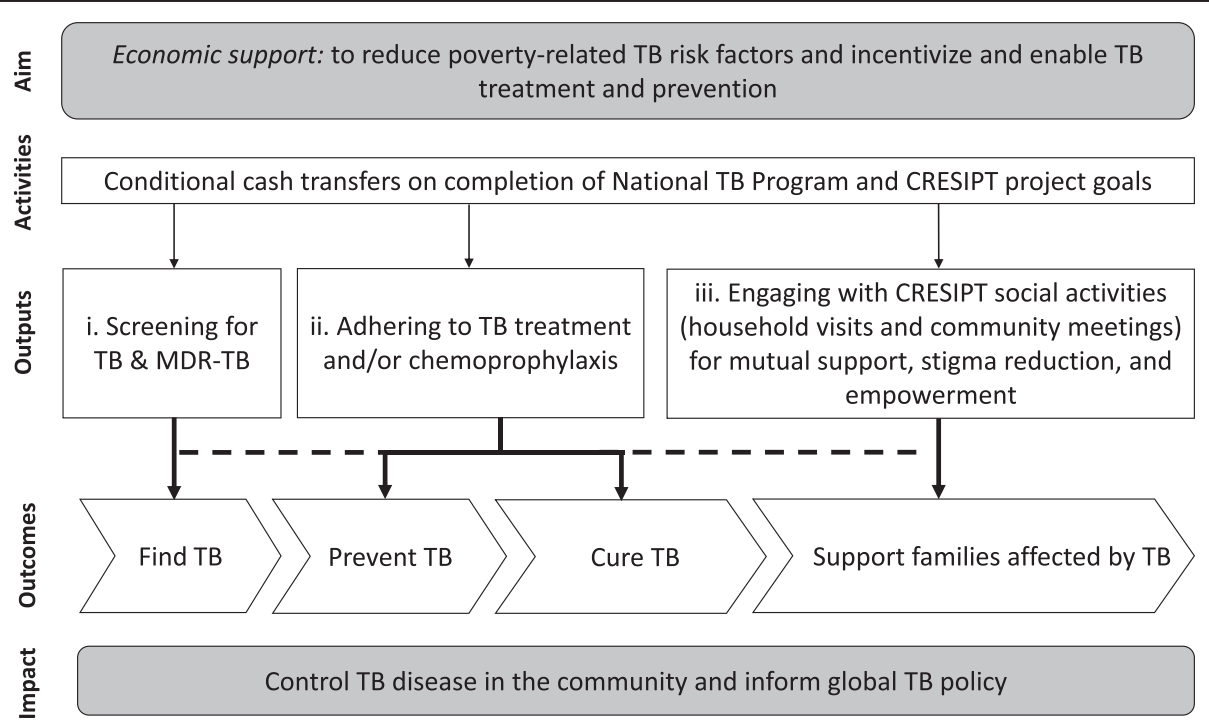

Fig. 1 Conceptual framework of the conditional cash transfer scheme within the CRESIPT project 
Table 1 CRESIPT consultation process

\begin{tabular}{|c|c|c|c|c|}
\hline $\begin{array}{l}\text { Formative } \\
\text { activities }\end{array}$ & Attendees & $\begin{array}{l}\text { Number } \\
\text { performed }\end{array}$ & $\begin{array}{l}\text { Number of } \\
\text { participants }\end{array}$ & Notes/details \\
\hline $\begin{array}{l}\text { A. Analysis of } \\
\text { evidence }\end{array}$ & $\begin{array}{l}\text { CRESIPT project research team and } \\
\text { international collaborators from Imperial } \\
\text { College London, London School of } \\
\text { Hygiene \& Tropical Medicine, and } \\
\text { John Hopkins School of Public Health }\end{array}$ & 3 & 28 & $\begin{array}{l}\text { Analysis and publication of ISIAT project results in } \\
2011 \text { [39] WHO-commissioned systematic review } \\
\text { of conditional cash transfer schemes' impact on } \\
\text { TB control in } 2011 \text { [20] plus updated review in } 2014\end{array}$ \\
\hline \multirow[t]{4}{*}{$\begin{array}{l}\text { B. Expert } \\
\text { consultation }\end{array}$} & Peruvian National TB program chiefs & 10 & 8 & $\begin{array}{l}\text { Steering meetings with regional and national TB } \\
\text { Program coordinators }\end{array}$ \\
\hline & $\begin{array}{l}\text { JUNTOS (www.juntos.gob.pe) } \\
\text { (Peruvian conditional cash transfer program) }\end{array}$ & 1 & 5 & $\begin{array}{l}\text { Discussed logistics and minimal impact evaluation } \\
\text { of conditional cash transfers for health and education } \\
\text { to female heads of rural households [5] }\end{array}$ \\
\hline & WHO Stop-TB partnership & 3 & 5 & Ongoing meetings and site visits \\
\hline & World Bank & 2 & 3 & $\begin{array}{l}\text { Ongoing meetings with senior World Bank economists } \\
\text { especially relating to cost-effectiveness considerations }\end{array}$ \\
\hline $\begin{array}{l}\text { C. Symposia and } \\
\text { conferences }\end{array}$ & $\begin{array}{l}\text { International multi-sectoral researchers } \\
\text { (including World and Pan-American } \\
\text { Health Organisation members) }\end{array}$ & 3 & 30 & $\begin{array}{l}\text { "Social protection interventions for TB control", UK, } \\
2012 \text { [19] WHO led policy consultation on social } \\
\text { protection for TB in Brazil, } 2013 \text { [16] TB Union World } \\
\text { Lung Health conference in France, } 2013\end{array}$ \\
\hline \multirow[t]{6}{*}{$\begin{array}{l}\text { D. Focus Group } \\
\text { Discussions (FGDs) }\end{array}$} & CRESIPT multidisciplinary team & 9 & 10 & $\begin{array}{l}\text { www.ifhad.org FGDs with the CRESIPT field team } \\
\text { research personnel }\end{array}$ \\
\hline & $\begin{array}{l}\text { Ex-TB patient civil society } \\
\text { "LUPORFAT" }\end{array}$ & 4 & 13 & \multirow{2}{*}{$\begin{array}{l}\text { Registered "Junta Directiva" (board of directors) of } \\
\text { ex-TB patient community representatives "Lucha } \\
\text { Por Familias Afectadas Por TBC" www.prisma.org } \\
\text { Structured interviews and FGDs }\end{array}$} \\
\hline & Key NGO Stakeholders & 4 & 5 & \\
\hline & CRESIPT project participants & 19 & 20 & $\begin{array}{l}\text { Including participatory community meetings and } \\
\text { training of facilitators }\end{array}$ \\
\hline & $\begin{array}{l}\text { Peruvian National TB program } \\
\text { health post staff }\end{array}$ & 18 & 12 & $\begin{array}{l}\text { Multi-disciplinary teams: co-ordinators, doctors, } \\
\text { nurses and technicians }\end{array}$ \\
\hline & Banks & 6 & 5 & $\begin{array}{l}\text { Account executives and social inclusion department } \\
\text { representatives }\end{array}$ \\
\hline $\begin{array}{l}\text { E. Field team } \\
\text { meetings }\end{array}$ & CRESIPT multidisciplinary team & 34 & 11 & $\begin{array}{l}\text { Covered operational field logistics and acceptance } \\
\text { of the intervention }\end{array}$ \\
\hline $\begin{array}{l}\text { F. Steering } \\
\text { committee }\end{array}$ & $\begin{array}{l}\text { CRESIPT multidisciplinary team \& } \\
\text { international Collaborators }\end{array}$ & 19 & 6 & $\begin{array}{l}\text { Twice monthly committee review of published literature } \\
\text { (including systematic review) and discussion of financial, } \\
\text { methodological and statistical design issues and potential } \\
\text { intervention improvements }\end{array}$ \\
\hline TOTAL & NA & 135 & NA & NA \\
\hline
\end{tabular}

While JUNTOS may be TB-inclusive (i.e. some TB patients will receive incentives as they are below this poverty threshold), it is neither TB-sensitive nor TB-specific [20]

$F G D$ focus group discussion

amean average

'We were unable to integrate our urban TB-specific intervention with JUNTOS' existing rural cash transfer scheme

\section{Acceptability}

To characterise operational challenges and the participants' perspectives, we performed an acceptability assessment using a mixed-methods approach. This involved the collection of quantitative and qualitative data from participants, a civil society group of ex-patient community representatives, CRESIPT project staff and local and regional Peruvian TB Program staff and co-ordinators.

\section{Ethical approval}

Approval was granted by the ethics committees of the Callao Ministry of Health, Peru; Asociación Benéfica PRISMA, Peru; and Imperial College London, UK. All interviewed participants gave written informed consent to participate in the study and for subsequent publication of anonymised data.

\section{Sample size}

The main outcome of this preliminary work of the CRESIPT study (reported elsewhere) was completion of TB chemoprophylaxis in household contacts of TB patients. TB patients had an average of five contacts and $25 \%$ of those eligible for TB chemoprophylaxis completed it [39]. Therefore, a priori, we calculated that 312 patients would give $80 \%$ statistical power to detect a $33 \%$ increase in the primary outcome comparing 


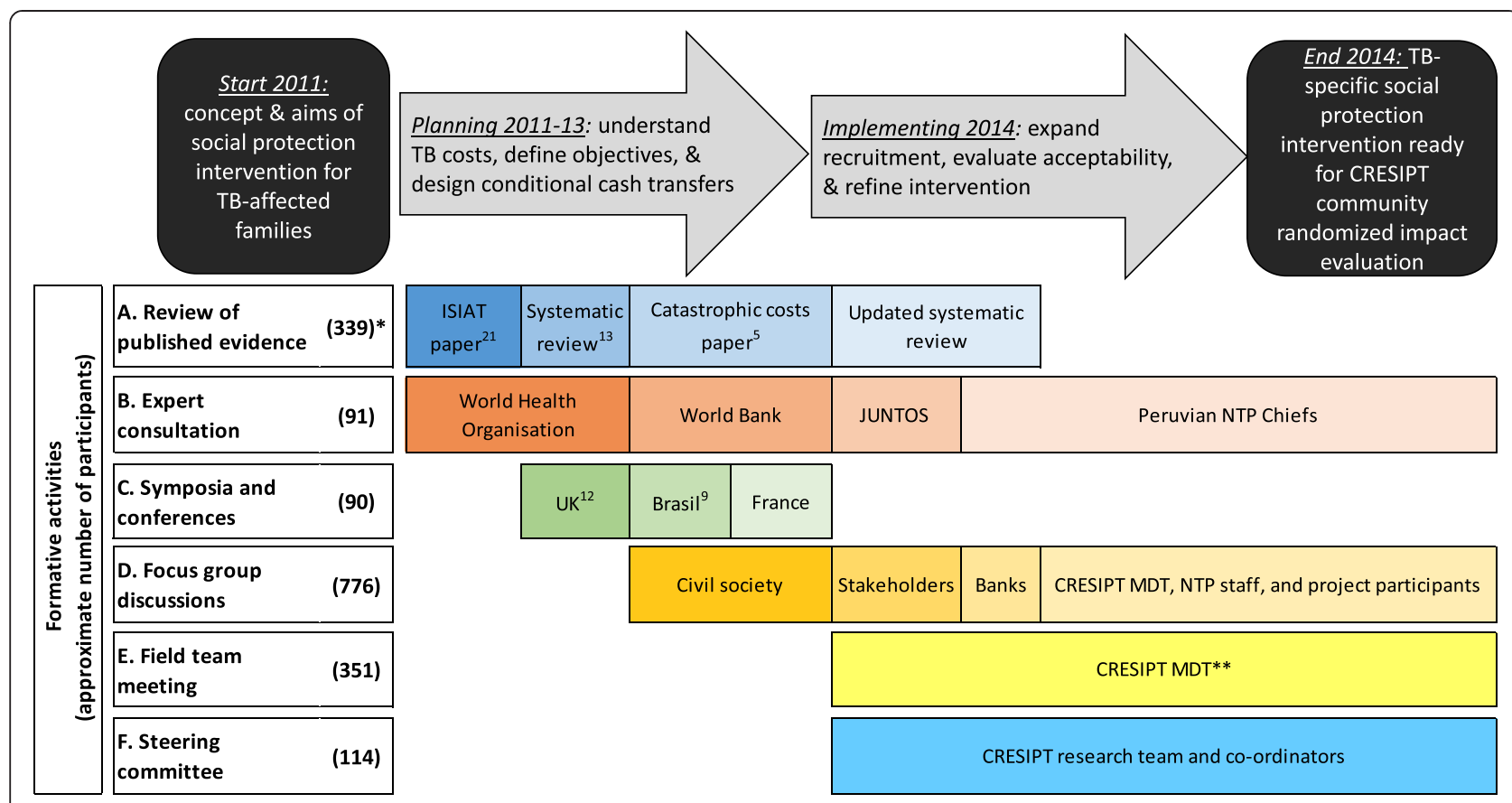

Abbreviations: MDT = multi-disciplinary team; NTP $=$ National TB program. ${ }^{*}$ Includes documents of potential interest reviewed or used as references ${ }^{* *}$ These weekly meetings have been an ongoing part of team activities for the past decade and are included here to illustrate when they focused solely on CRESIPT

Fig. 2 Flow diagram of CRESIPT project activities during planning, implementation and refinement of the social protection intervention

intervention versus control households with two-sided $5 \%$ significance. The 312 patients recruited were randomly assigned in a 1:1 ratio to the intervention arm (normal standard of care from the National TB Program plus socioeconomic intervention) and control arm (normal standard of care from the National TB Program).

\section{Results: designing and implementing the intervention}

Designing the conditional cash transfers

Targeting

To provide evidence to assist national TB programs considering implementing TB-related socioeconomic interventions, our intervention exclusively targeted TB-affected households (i.e. was "TB-specific") rather than targeting all households living below the poverty line. The reasons for this decision were: encouraging results from the TB-specific ISIAT project; [39] the urgent need for impact assessment and operational evidence for TB-specific socioeconomic interventions; the lack of existing TB-specific or TB-sensitive socioeconomic initiatives with which to feasibly collaborate in Peru; and the achievability of focusing on relatively small numbers of TB patients versus much larger, operationally unmanageable numbers of people at risk of $\mathrm{TB}$ in the wider community [52]. In addition, it was expected that by working exclusively with TBaffected families we would generate evidence concerning those sections of the community most at risk of TB.

\section{Cash delivery strategy}

Cash transfers directly into bank accounts were selected as the most locally-appropriate way to deliver economic support because in the impoverished shantytown communities of the study site there were many: local bank agencies; food or material vouchers had poor accessibility and acceptability; direct cash transfers posed a security risk; and transfers using mobile-phone technology potentially overlooked the most vulnerable patients [53] and were prone to handset loss/theft, damage, or faults.

\section{Cash transfer size}

Deciding on the size and duration of cash transfers was difficult because this has varied considerably in past projects $[47,49]$. Learning from similar regional projects [45, 49], our local catastrophic costs findings [7], and ongoing liaison and site visits from key policy-makers from WHO, Pan-American Health Organisation and the World Bank, we aimed to completely mitigate TBrelated direct out-of-pocket expenses, which was expected to be equivalent to $10 \%$ of median TB-affected household annual income in the study site [7]. This 
Table 2 Available evidence and CRESIPT project operational decisions relating to cash transfers

The available evidence - what do we know?

Cash transfer $\quad$ - Cash transfer schemes were implemented in Latin America in the 1990s to tackle

schemes

the socioeconomic consequences of financial crises [21]. Schemes include: Bolsa Familia (Brasil, 1995); Oportunidades (Mexico, 1997); Red de Protección Social (Nicaragua, 2000-2005); Bono de Desarrollo Humano (BDH Ecuador, 2004); Red Solidaria (El Salvador, 2005); and JUNTOS (Peru, 2005)

- Our systematic review revealed only one controlled trial of TB-specific cash transfers from South Africa that showed no significant increase in successful TB treatment outcome [41]. During treatment, vouchers (15 US Dollars) that could be exchanged for foodstuffs were given to patients by local health post nursing staff. The authors opted for vouchers over cash due to: posing a lower security risk; not being able to be spent on unhealthy items such as alcohol or cigarettes; being easy to monitor; and "public health sector clinics would not have bank accounts, making electronic transfers difficult" [41]

Conditionality - Cash transfers can be unconditional, conditional (requiring specific behavioural, education of cash transfers or health actions) or combined $[46,47]$

- Unconditional cash transfer schemes include: Ecuador's BDH targeting those below poverty threshold or by location; $[48,49]$ and a village bank loan scheme for TB-affected households in Cambodia [50]

- Conditions can be "hard" (if the condition is not met, the transfer is not made) or "soft" (less stringent conditions where transfers may be made even when a condition is unmet). Soft conditionality may be preferable in settings with poor healthcare infrastructure $[21,46,51]$

How much - Minimal evidence exists on the size of cash transfers. In Latin America, total amounts have cash to give varied widely in previous projects: 6-10\% of annual income in Ecuador; [49] 21.8\% in Mexico; and $29.3 \%$ in Nicaragua [47]

When to give - Most initiatives deal more with poverty than a finite illness such as TB, so evidence of cash duration and frequency of TB-specific cash transfers is scarce. Longer duration and more frequent cash transfers may have greater impact in TB-affected households [31]

Operational decisions for implementation of the CRESIPT project intervention

- We investigated the use of food or other vouchers/cards but found very few existing systems in the study site. Those that were in place could only be redeemed in supermarkets (felt in FGDs to be inappropriate for the study population due to infrequent use, limited access and higher costs of goods)

- Based on our experiences and the limited published evidence, we opted for a bank cash transfer scheme. Bank transfers reduce the likelihood of fraud, robbery or security risk (a concern in impoverished shantytowns in Lima, Peru) $[37,41]$ and are a reliable way to maintain accurate transfer records for cost-effectiveness analysis. We also felt opening a bank account and having freedom of choice to decide on how transfers were spent was empowering [44]

- We decided not to impose conditions on how the cash transfers were spent Successfully funded social protection interventions related to TB (especially MDR TB) have mainly focused on mitigating non-medical direct costs associated with having TB such as food or travel $[17,44]$. There is some evidence that even when money rather than food vouchers is given as a form of social protection, it is commonly spent on food and travel costs anyway [45]

- Perú has an exemplary, well-established and organised National TB program. Learning from ongoing collaboration with regional heads of the TB program, we decided that our cash transfers conditions would relate to National TB Program treatment and prevention goals and selected project activities

- We chose to use conditional cash transfers that mixed both hard and soft conditions to be more inclusive: "hard" in that if participants met the condition with "perfect behaviour" then a double cash transfer was provided and "soft" in that if participants met the condition with adequate behaviour, then a simple cash transfer incentive was provided (Fig. 4a and b)

- We aimed to establish an amount for the cash transfers that was too small to act as a perverse incentive [34, 35], but large enough so that poverty-related TB risk factors in TB-affected households were reduced and the households were both incentivized and enabled to achieve National TB program and project goals

- We decided to provide the majority of the cash transfer incentives in the intensive treatment phase (the first 2 months of treatment) and to continue monthly cash transfers specific for treatment adherence throughout treatment. This meant the intervention was designed to increase equity for people with TB-HIV co-infection and MDR TB whose treatment lasted longer than 6 months 
amount was: empirically believed to be too small to act as a perverse incentive; [34, 35] affordable for a TB program in a low income country (expert opinion suggests that a socioeconomic intervention that adds less than $50 \%$ to the cost of biomedical treatment but reduces TB risk by 30-40 \% would be likely to justify policy change and widespread implementation); [54, 55] large enough so that poverty-related TB risk factors in TB-affected households may be reduced; and that incentivized and enabled TB-affected households to achieve the shared goals of the Peruvian National TB Program and CRESIPT project.

\section{Cash transfer timing}

We designed the intervention so that cash transfers would be provided throughout treatment but weighted towards the first 2 months, when TB-affected households incur the majority of hidden costs (Additional file 1: Figure S1a and b) $[7,56,57]$.

\section{Cash transfer conditions, levels and responsiveness}

We stratified cash transfer incentives into "double" and "simple" incentives. Double incentives were made for meeting the condition "optimally" (i.e. monthly adherence missing less than two daily tablets). Simple incentives were made for meeting a condition "acceptably" (i.e. monthly adherence in which two or more tablets had been missed but the patient had not abandoned treatment). Figure 3 summarizes seven different potential scenarios of TB patients and the total amount of cash transfer incentives they would receive. Were a participant with non-MDR $\mathrm{TB}$ to receive all the double incentives available throughout treatment, they would receive a total of 230 US Dollars; for all simple incentives, they would receive a total of 115 US dollars (Additional file 1: Figure S1a

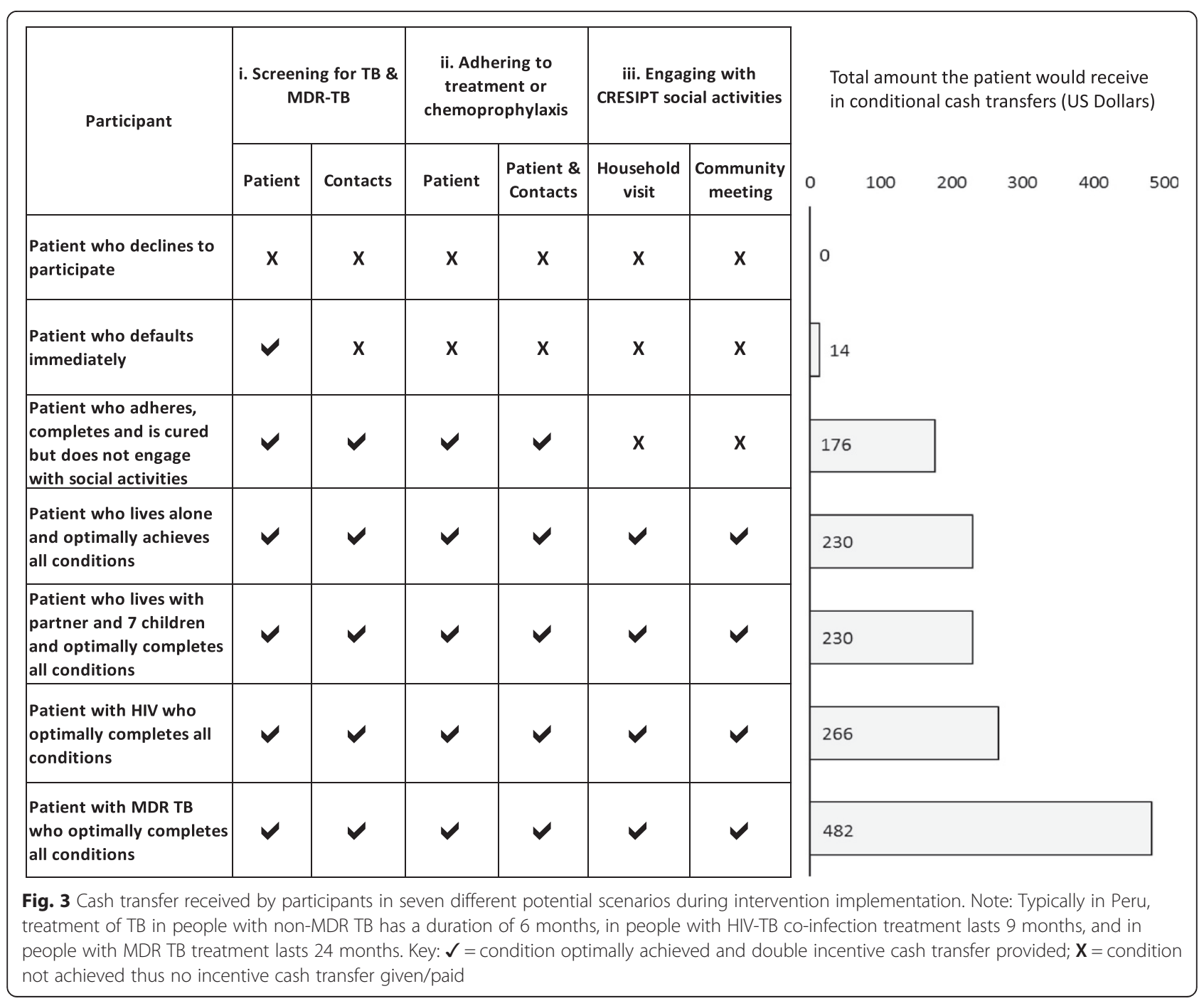


and b). In situations in which TB treatment routinely extended beyond 6 months, such as HIV-TB coinfection (9 months) or multi-drug resistant (MDR) TB (18 to 24 months), cash transfers continued throughout the duration of treatment. The decision to stratify simple and double incentives was taken in order to encourage a positive feedback loop of behaviour change through graded incentives whilst increasing the opportunity for vulnerable patient groups to receive cash transfers even when they could not achieve conditions optimally.

\section{Implementation of the conditional cash transfers Banks}

Of 10 banks visited, formal meetings were organised with four that aimed to: create a relationship with the bank to achieve sustainable cash transfers throughout the study; identify charge-free appropriate accounts; create a "virtual" way of opening accounts to minimize paperwork, time spent "in branch" and travel-related patient costs; establish a mutually suitable day on which to accompany patients to open accounts; and to clarify the bank's accessibility in our study sites (i.e. branches and agencies).

The banks we consulted raised similar concerns about the proposed intervention, including: infection risk; cash transfer flow; and difficulties opening accounts with patients who have no national identification, fixed abode, or are illiterate. We initially chose one bank that appeared to be more likely to overcome these issues because it had a social inclusion department with previous involvement in successful microfinance initiatives.

\section{Opening bank accounts}

Recruited patients with a negative sputum smear microscopy test (indicating low infectiousness) were accompanied by our project staff to open a bank account. The account holder's details were then relayed to our project office with a copy of the bank's original documents. In the case that the patient was a minor, did not have legal capacity, wished for another household member to be the named bank account holder, or had prolonged sputum smear positivity, then a household member was selected by the patient or household to be the named bank account holder. Patient transport and time costs were reimbursed by our project.

\section{Cash transfer administration}

The patient's incentive card (Additional file 1: Figure S1a and b) was updated by the field nurses when each condition was achieved. Confirmation of completion was made through liaison with the patient, review of CRESIPT project records (e.g. participatory community meeting attendance) and Peruvian National TB Program records and treatment cards (e.g. medication adherence verification).
Signed incentives cards were returned to a project administrator who double digitized the data. Thus, a weekly list of patients, their bank account details and required transfers was generated. The same day, this list was submitted electronically to a member of the social inclusion department of the bank, and the virtual transfers made. The transaction codes and receipts generated were double digitized in the CRESIPT project database and delivered to the patients in the health post by the CRESIPT field nurses.

\section{Recruitment}

From February to August 2014, we expanded project activities from 2 to 32 communities. As per the a priori sample size calculations and study protocol, 312 consecutive TB patients from the study site were invited to participate of whom 149 were randomized to receive the socioeconomic intervention. $12 / 149$ (8 \%) patients declined to participate, 2/149 (1 \%) died prior to recruitment, and $2 / 149$ (1 \%) were recruited and subsequently did not complete follow up. Thus, 133/ 149 (89 \%) were recruited and participated throughout the study period. The number of patients declining to participate was higher in urban than in periurban communities (15\% [95\% CI 6-23] versus $5 \%$ [95\% CI 1-10\%] respectively, $p=0.04)$. Of the 133 participants, 9/133 (7 \%) had MDR TB, 5/133 (4 \%) were HIV positive, and 7/133 (5\%) were diabetic.

\section{Cash transfers achieved up to 1st July 2015}

Of 1299 potential cash transfers, 964 (74 \%) were achieved (of these, 885/964 [92 \%] were achieved optimally and 79/964 [8 \%] sub-optimally), 259 (19\%) were not achieved, and 76 (7 \%) were yet to be achieved. Thus, 964 conditional cash transfers totalling 61,120 Peruvian Soles (20,373 US dollars) were made to TBaffected households for meeting the conditional goals of the Peruvian National TB Program and CRESIPT project (Fig. $4 \mathrm{a}$ and b). The average cash transfer amount received by each TB-affected household over the course of the intervention was \$173 USD.

\section{Discussion: lessons learnt and persisting knowledge gaps}

The implementation and acceptability assessment identified strengths and limitations of our theoretical approach during the design of CRESIPT. The lessons that emerged are grouped into successes, challenges and refinements in Table 3, which aim to inform the design of future studies and, ultimately, allowed us to identify persisting knowledge gaps in this field (Table 4).

\section{Successes}

This project generated evidence that conditional cash transfers to TB patients were logistically achievable in 


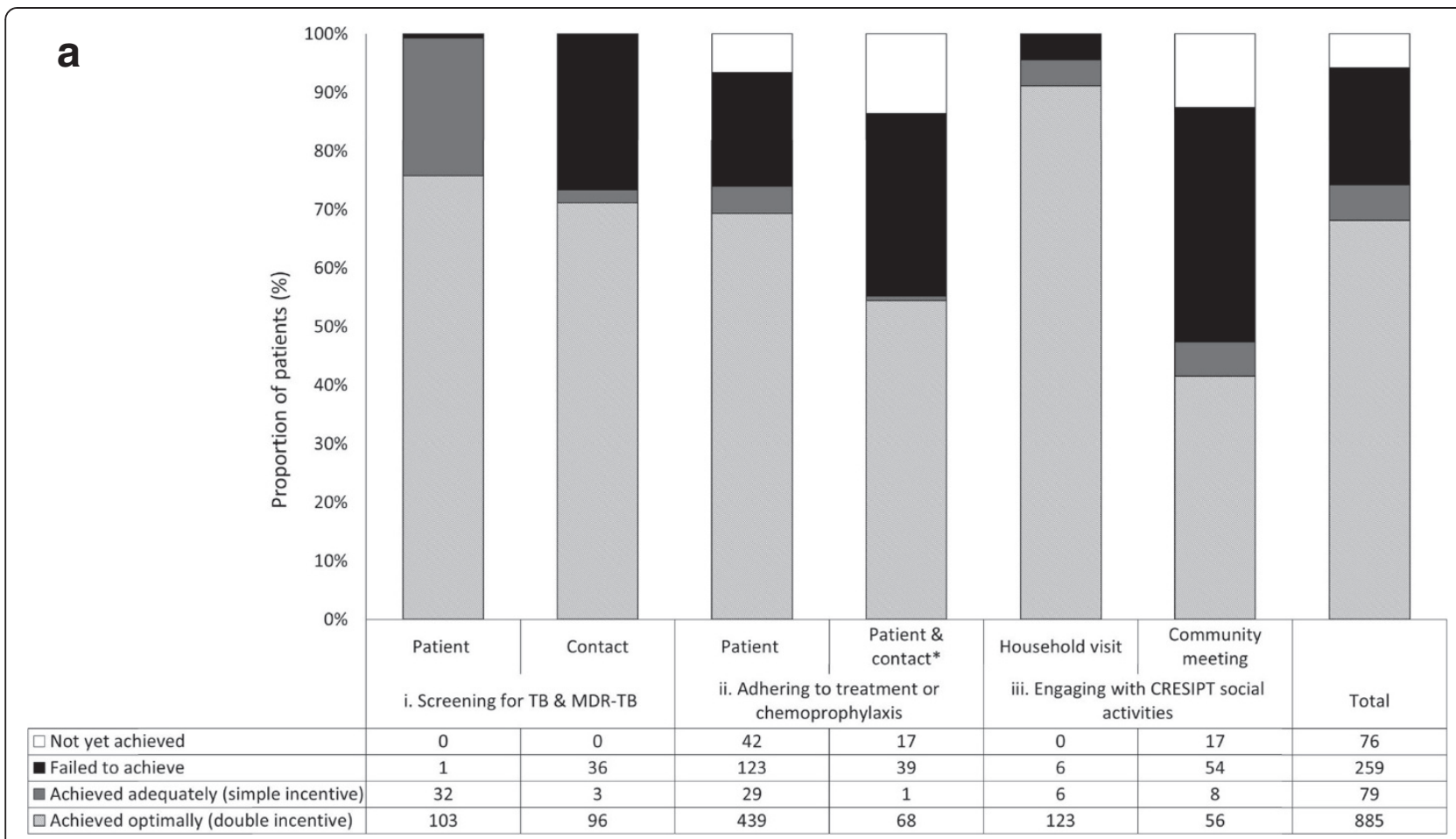

*This condition that was achieved when the patient finished their treatment and $100 \%$ (double incentive) or $\geq 80 \%$ of the household contacts who were eligible for and started chemoprophylaxis, finished their chemoprophylaxis. At the time of writing, less than a third of patients or contacts had finished their treatment or chemoprophylaxis courses respectively

\section{b}

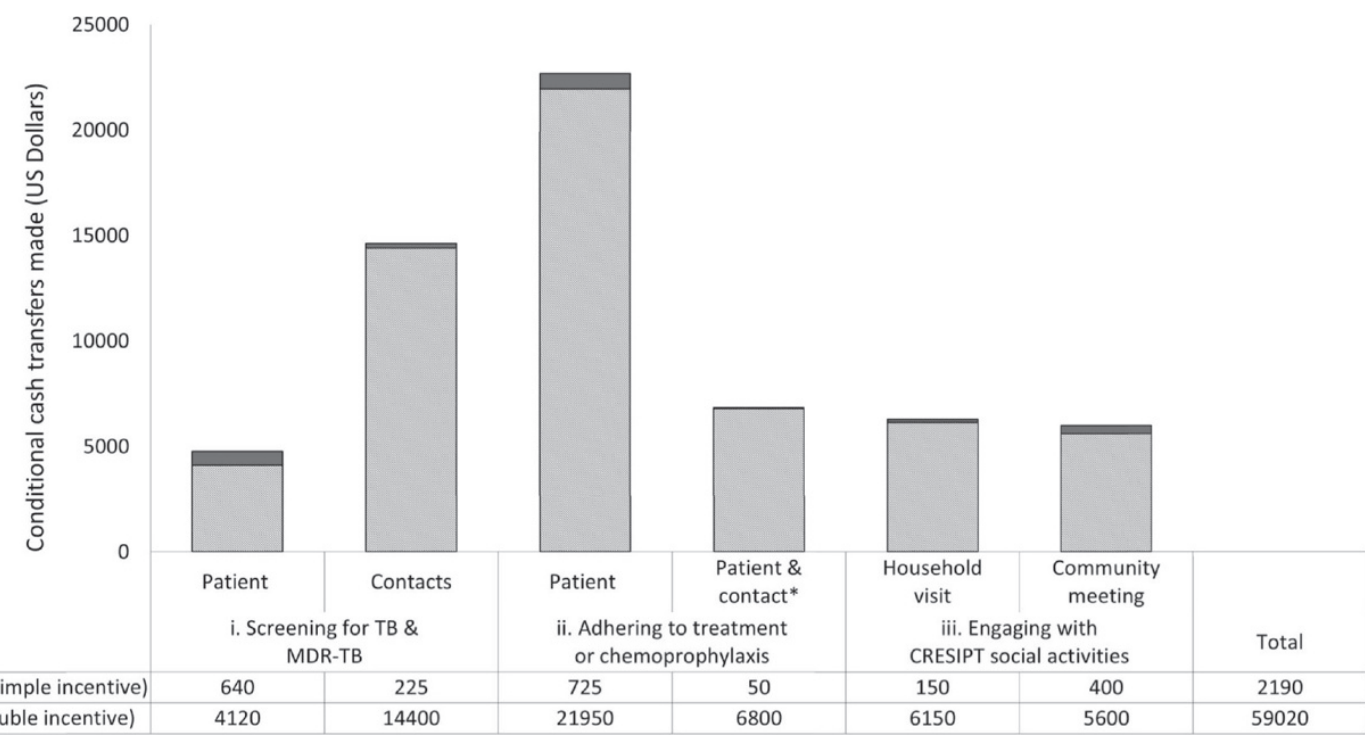

Achieved adequately (simple incentive)
$\square$ Achieved optimally (double incentive) 4120 14400

21950
6800 *This condition that was achieved when the patient finished their treatment and $100 \%$ (double incentive) or $\geq 80 \%$ of the household contacts who were elist
chemoprophylaxis. At the time of writing, less than a third of patients or contacts had finished their treatment or chemoprophylaxis courses respectively

Fig. 4 a Proportion of patients optimally achieving (double incentive), adequately achieving (simple incentive) and not yet achieving project conditions. b Total amount provided to patients by conditional cash transfers in total and for each condition achieved

impoverished shantytown communities of Lima, Peru. The intervention considerably supplemented small monthly food baskets given unconditionally to TB patients by the Peruvian National TB Program.
Through regular steering meetings, focus group discussions and contact in the health posts, strong collaboration was achieved between our team, banks and the Peruvian National TB Program: 
Table 3 Successes, challenges and refinements of the cash transfer incentive dimension of the socioeconomic intervention

\begin{tabular}{|c|c|c|c|}
\hline & Successes & Challenges & Refinements \\
\hline $\begin{array}{l}\text { New } \\
\text { evidence }\end{array}$ & $\begin{array}{l}\text { New experience and evidence was generated that } \\
\text { TB-specific cash transfers for TB-patients were feasible } \\
\text { in this study setting }\end{array}$ & $\begin{array}{l}\text { There was a lack of available evidence and thus clarity } \\
\text { when prioritising the output of the cash transfers in } \\
\text { these TB-affected households. Thus, deciding on the } \\
\text { cash transfer amounts and timing was difficult }\end{array}$ & $\begin{array}{l}\text { Following previous and updated analysis of hidden } \\
\text { costs and income of TB-affected households [7], } \\
\text { cash transfer amounts were increased with the aim } \\
\text { of reducing their poverty-related TB risk factors }\end{array}$ \\
\hline Collaboration & $\begin{array}{l}\text { There was strong multi-sectorial collaboration with Peruvian } \\
\text { National TB Program and bank staff, allowing multiple, virtual } \\
\text { cash transfers to be made and recorded, reducing fraud and } \\
\text { security risks }\end{array}$ & $\begin{array}{l}\text { Account maintenance charges were introduced by } \\
\text { the bank during implementation of the intervention } \\
\text { and delays in cash transfers eroded participants' trust } \\
\text { in the project }\end{array}$ & $\begin{array}{l}\text { We changed our bank service provider: the new } \\
\text { bank had better accessibility and no charges. We } \\
\text { self-imposed penalties on our project for late cash } \\
\text { transfers (participants gained additional transfers) }\end{array}$ \\
\hline \multirow[t]{3}{*}{$\begin{array}{l}\text { Cash } \\
\text { transfers }\end{array}$} & $\begin{array}{l}\text { Cash transfers lasted throughout treatment, increasing } \\
\text { equity for people with TB and HIV co-infection or MDR TB, } \\
\text { whose treatment duration extended beyond } 6 \text { months }\end{array}$ & $\begin{array}{l}\text { As a research team, we had limited experience of } \\
\text { cash transfer interventions or working with new } \\
\text { urban study communities }\end{array}$ & $\begin{array}{l}\text { Achieving a balance between operational simplicity } \\
\text { and complex TB-affected household needs was } \\
\text { challenging }\end{array}$ \\
\hline & $\begin{array}{l}\text { Opening a bank account was a first-time experience for } \\
\text { many of the participants and qualitative participant feedback } \\
\text { suggested that this was perceived as an empowering action, } \\
\text { especially for female members of the household who have } \\
\text { previously been shown to be a vulnerable subpopulation in } \\
\text { the study setting [5] }\end{array}$ & $\begin{array}{l}\text { Feedback suggested that patients would prefer } \\
\text { immediate gratification for completion of conditions } \\
\text { rather than delayed cash transfer bank payments }\end{array}$ & $\begin{array}{l}\text { Immediate incentives were provided for attending } \\
\text { participatory community meetings (including food } \\
\text { baskets and high-quality vouchers documenting } \\
\text { the date and amount owed to the participant) }\end{array}$ \\
\hline & & $\begin{array}{l}\text { Project conditions requiring all members of the } \\
\text { TB-affected household to participate were } \\
\text { poorly achieved and not equitable due to different } \\
\text { household sizes }\end{array}$ & $\begin{array}{l}\text { We combined conditional and unconditional cash } \\
\text { transfers. Conditions requiring household participation } \\
\text { were altered to be responsive to household size: } \\
\text { incentives given were refined to be given per } \\
\text { household member involved }\end{array}$ \\
\hline $\begin{array}{l}\text { Inclusiveness } \\
\text { and high risk } \\
\text { groups }\end{array}$ & $\begin{array}{l}\text { The intervention was holistic and household-centred } \\
\text { because, in addition to cash transfers, it provided community } \\
\text { meetings consisting of educational workshops (covering themes } \\
\text { such as TB treatment, transmission, prevention and also financial } \\
\text { themes such as responsible household budgeting in an } \\
\text { interactive manner) and TB Clubs (mutual support aiming to } \\
\text { reduce stigma and increase empowerment, reported separately) }\end{array}$ & $\begin{array}{l}\text { "High risk" patients in more urban communities } \\
\text { were difficult to engage with (especially the } \\
\text { formerly-incarcerated, drug- or alcohol-dependent } \\
\text { and gang members) }\end{array}$ & $\begin{array}{l}\text { Participatory community meetings for patients with } \\
\text { MDR TB were established and increasing social } \\
\text { support was provided to other high risk patients } \\
\text { (including the homeless, drug or alcohol dependent, } \\
\text { those with poor adherence and/or lack of engagement } \\
\text { with our project) }\end{array}$ \\
\hline
\end{tabular}


Table $\mathbf{4}$ Lessons learnt and persisting research gaps

\begin{tabular}{|c|c|}
\hline Lessons learnt & Research gaps \\
\hline \multirow[t]{2}{*}{$\begin{array}{l}\text { Social protection interventions for TB control require } \\
\text { inter-sectorial collaborations }\end{array}$} & $\begin{array}{l}\text { - What are the most effective and cost-effective partnership models for welfare } \\
\text { and TB control bodies? }\end{array}$ \\
\hline & $\begin{array}{l}\text { - What are the best ways to integrate poverty reduction strategies and biomedical } \\
\text { activities for TB control? }\end{array}$ \\
\hline \multirow{6}{*}{$\begin{array}{l}\text { TB-specific conditional cash transfers are feasible and } \\
\text { safe, but logistically complex }\end{array}$} & -What is the role of conditions in achieving the intervention objectives? \\
\hline & $\begin{array}{l}\text { - Are conditional, unconditional or combined cash transfers preferable and how does } \\
\text { this depend on the settings in which the cash transfer program is implemented? [62] }\end{array}$ \\
\hline & -What conditions are too hard to achieve for TB patients despite being well rewarded? \\
\hline & $\begin{array}{l}\text { - What is the best way to balance the conditions for the cash transfers in order that } \\
\text { they reflect both the priorities of patients and their households, and the priorities of } \\
\text { researchers and policy makers? [63] }\end{array}$ \\
\hline & $\begin{array}{l}\text { - What is the role of the size and timing of cash transfers on the impact of the } \\
\text { intervention? }\end{array}$ \\
\hline & -What is the effectiveness and cost-effectiveness of different delivery mechanisms? \\
\hline \multirow[t]{3}{*}{$\begin{array}{l}\text { TB-specific conditional cash transfers can be } \\
\text { challenging to deliver to difficult-to-reach populations }\end{array}$} & $\begin{array}{l}\text { - What are the optimal ways to adapt conditional cash transfer settings targeted at } \\
\text { hard-to-reach populations in challenging urban environments characterised by } \\
\text { violence, drug-addiction and marginalisation? }\end{array}$ \\
\hline & $\begin{array}{l}\text { - Should social protection interventions only be offered to high-risk patients or is it } \\
\text { more cost-efficient to offer them to all patients plus an enhanced intervention to } \\
\text { high-risk patients? }\end{array}$ \\
\hline & $\begin{array}{l}\text { - Is cash without social support sufficient to reach high-risk-patients or is social support } \\
\text { necessary? }\end{array}$ \\
\hline \multirow{3}{*}{$\begin{array}{l}\text { Health and financial management education are } \\
\text { necessary and ethically appropriate }\end{array}$} & -Would cash transfers have the same impact even without an educational component? \\
\hline & $\begin{array}{l}\text {-What is the empowering factor of the cash transfers to TB patients: 1) receiving } \\
\text { cash; or 2) being acknowledged and seen as individuals with rights and needs? }\end{array}$ \\
\hline & $\begin{array}{l}\text { - What is the aspect of the social protection intervention most likely to impact on TB } \\
\text { prevention and cure: a) the economic dimension of cash transfers; b) the social } \\
\text { dimension of home visits and community meetings; or c) both? }\end{array}$ \\
\hline
\end{tabular}

"The CRESIPT project and Peruvian National TB Program are complementary and should continue to support each other in a common goal." [Peruvian National TB Program Regional Chief].

Such ongoing collaboration and adaptation to stakeholder and participant feedback helped the project to be more locally-appropriate, responsive and patient-centred.

The conditional cash transfers were facilitated by multisectorial collaboration including with the bank's social inclusion department. Multiple, regular, simultaneous, virtual cash transfers were achieved through online banking that generated a digital record, reducing the likelihood of fraud. Because field team staff were not directly carrying or giving cash or cash-equivalents (such as cash vouchers or cheques), cash transfers were a secure method of providing incentives. The majority of participants did not have bank accounts [58] and some patients described the act of opening a bank account as empowering:

"...especially for female patients, who are not normally the financial decision-makers of the households in

\section{these communities" [CRESIPT Project Nurse Technician].}

The socioeconomic intervention was holistic and household-centred with the economic dimension of cash transfers being complemented by social support activities including household visits and participatory community meetings [59]. In addition to TB prevention and control messages, an educational component was an important element of the participatory community meetings, in which participants were involved in educational activities concerning: managing a household budget; spending and saving responsibly; and meeting the conditions for cash transfers. This TB-related and financial education was highly rated by participants and perceived as an ethically sound accompaniment to cash transfers by CRESIPT project staff and TB-affected households:

"I understood and learnt more, and saw that I was not alone" [TB-Affected Household Member]; 
"The meetings generated good solidarity and camaraderie" [TB-Affected Household Member].

Our experience is consistent with reports that financial incentives should be complemented by education or "social marketing" if health objectives are to be achieved. Further research is needed to investigate the relative importance of health and financial education on the impact of cash transfer interventions aiming to improve health.

\section{Challenges and refinements}

The lack of published evidence of similar studies was particularly challenging for the implementation of TBspecific cash transfer incentives in resource-constrained communities.

\section{Cash transfer targeting}

The significantly higher number of patients declining to participate seen in the urban rather than peri-urban communities may have been due to the fact that CRESIPT project activities were new in this area or reflect distinctions between these communities:

\section{"We don't fully understand the demographic differences and challenges between the urban and peri-urban communities" [CRESIPT Project Investigator]}

The field staff reported that some patients were not willing to participate because: i) they thought that CRESIPT project staff were part of a governmental body; ii) they did not want to register their true address with either the TB program, a bank, or the CRESIPT project in order to keep "under the radar" [CRESIPT Project Nurse] especially those formerlyincarcerated or involved with "pandillas" (drugs gangs); iii) they did not wish our team to visit their home because their household was unaware of their diagnosis or they frequently moved location; or iv) the incentives were insufficient to match the money they lost for participating in project activities and, more importantly, continuing on their treatment. In addition, patients with recognised "high-risk" factors for treatment default such as prolonged treatment courses (e.g. MDR TB and/or HIV), mental illness, illegal drug use, homelessness, or being formerlyincarcerated were difficult to recruit and retain. Because these patients did not consent to participate we could not formally characterise their reasons for declining. This lack of engagement and formal feedback is concerning given that such groups may have benefited most from the intervention.
"Conditions are appropriate but you need to provide additional support to those people who find it harder to meet those conditions" [Ex-TB Patient Civil Society Representative]

\section{"Some patients would never open a bank account because they don't want to register their name" [CRESIPT Project Nurse] \\ "IA negative aspect of the CRESIPT project intervention is] giving an economic incentive to a patient with drug-dependency and for that matter any other benefit/incentive such as food baskets (which some of these patients sell to buy drugs)" [Peruvian National TB Program Nurse]}

To combat some of these issues, extra care was taken during the informed consent process to reassure potential participants that the CRESIPT project team is a non-governmental research organisation with no connections to the justice system and that no project activity, especially household visits, was mandatory. In an attempt to address the needs of participants with HIV and/or MDR TB, we explicitly specified that cash transfers for adherence were provided throughout treatment, regardless of treatment duration. This longevity meant that TB-affected household support, staff-household relationship and financial benefits of the cash transfers were refined to be more equitable and responsive to the ongoing needs of patients with HIV and MDR TB.

Hard-to-reach populations and/or difficult urban settings such as those in which our intervention was implemented, may be characterised by violence, illegal drug use and severe marginalisation that are also associated with TB. These populations and those with comorbidities (such as diabetes, HIV, or mental illness) and/or MDR TB may require differential levels of intervention including prolonged or enhanced conditional cash transfers and social support. Future studies may investigate the barriers, feasibility and impact of delivering TB-specific socioeconomic interventions to challenging, vulnerable groups in such settings.

\section{Cash transfer delivery strategy}

We changed bank-provider because the initial bankprovider: had limited geographical accessibility; provided inconsistent information "in branch" (resulting in some patients opening accounts with maintenance fees); was reported during feedback sessions to have been stigmatizing towards patients, not due to TB (the branch staff were unaware of patients' diagnoses) but possibly due to other sociocultural factors such as poverty or appearance; and introduced account maintenance charges to previously charge-free accounts. 
"Some patients lost faith in the project due to the hidden bank charges" [CRESIPT Project Nurse].

The new bank-provider, while not having a specific social inclusion department, provided improved coverage and accessibility because of a greater density of agency micro-branches in local shops that facilitated participant transactions. While the new bank-provider overcame the challenges described above, these experiences have led us to question whether banks are the most appropriate delivery strategy. Indeed, conditional cash transfer programs in Sub-Saharan Africa have predominantly used specified pay points to pay participants in cash rather than banks which may be less accessible to the poor and may have user fees [60]. However, banks have been the favoured partner agent in existing conditional cash transfer programs in Peru (JUNTOS), Brasil (Bolsa Familia) and Mexico (Progresa) with the co-ordination of national cash transfer programs being centralised through national banks in these countries [60]. This level of coordination may only be suitable in countries with comparatively developed financial infrastructure, information and communications technologies, and accessibility to bank branches or micro-agencies. We have reviewed other modalities of conditional cash transfers in greater detail elsewhere [20]. Future research into implementation of socioeconomic interventions may compare the effectiveness and cost-effectiveness of cash delivery mechanisms including mobile phone vouchers, mobile banking, automated or other pay points, or innovative strategies, for which rigorous evidence is currently lacking. To achieve optimal impact, implementers of conditional cash transfer programs may work more closely with the local communities and civil societies to establish how a program can be adapted to be appropriate and acceptable in that specific setting.

\section{Cash transfer size}

During focus group discussions, the internal research committee debated what the most important objective of cash transfers is: mitigating TB-related costs; avoiding catastrophic costs; or reducing poverty-related TB risk factors. This confounded deciding the cash transfer amounts. To address this challenge, we analysed TB patients' costs, which demonstrated that direct out-of-pocket expenditure was $10 \%$ of that household's annual income [7]. These results, together with additional data characterising annual household income for TB-affected households in the study site, informed the cash transfer amount necessary to match direct out-of-pocket expenditure and subsequently avoid catastrophic costs. The optimal cash transfer size is likely to depend on the intervention setting and proposed outcomes of the intervention. This will require baseline evaluation of local TB-related costs prior to planning for and implementing cash transfers of suitable amounts. Further research is required to evaluate how cash transfer size affects intervention impact and cost-effectiveness [61]. It is noteworthy that the strategy we adopted in this research was a "costs-mitigation" rather than a "poverty-reduction" strategy and involved a cash transfer amount that were appropriate and feasible for the local setting. While long-term poverty reduction would be an appealing additional goal, this would likely require greater socioeconomic support than national TB programs could afford.

\section{Cash transfer timing}

During focus group discussions, the delay between incentivized behaviour and cash transfers was noted as a barrier to achieving project conditions due to the lack of a tangible "reward" and accompanying positive reinforcement loop. For example, when a household attended a participatory community meeting, it could be 1 to 2 weeks before they received the corresponding cash transfer.

\section{"Patients want immediate and tangible gratification on the same day as they complete their condition" [Ex-TB Patient Civil Society Representative].}

Cash transfers were initially delayed due to the flow of information from the field, to the research office, to the bank. While cash transfer flow improved during the project, patients and households stated that such delays made household budgeting difficult:

"Due to the initial cash transfer delays, some patients didn't get the money when they most needed it" [CRESIPT Project Nurse].

Consequently, we increased the speed of the cash transfers and plan to instigate a system during CRESIPT in which on the same day that a household attends a community meeting, they receive a small high-protein food basket and a high-quality certificate-like voucher detailing the amount and date by which the cash transfer would be made.

Participants reported that they would prefer to receive cash transfers at the beginning of the month for their adherence in the subsequent month rather than wait until the end of the month. As has been reported in other settings [45], the waiting was perceived as financially stressful and, on occasion, demoralising. Learning from this setting-specific qualitative feedback, in the planned CRESIPT study in these same communities, we will combine unconditional monthly cash transfer provided to all $\mathrm{TB}$ patients taking treatment with supplementary conditional cash transfers for meeting CRESIPT project and National TB Program conditions. Furthermore, we have self-imposed penalties on our project if incentives do not reach the patient's bank account within 1 week of 
confirmation that the condition has been met. Specifically, if a delay occurs, their cash transfer is doubled.

\section{Cash transfer conditions, levels and responsiveness}

Project conditions requiring involvement of "100\%" of the TB-affected household in order to receive the cash transfer (e.g. attendance at participatory community meetings) were hard to achieve. In addition, the amount of these cash transfers was fixed and independent of household size (see Fig. 3) and thus felt to be inequitable because larger households received a lower cash transfer amount per household member. There was, therefore, a perceived challenge in balancing operational simplicity (e.g. fixedamount incentives) while responding to patient household needs (e.g. variable incentive depending on household size). Consequently, on the basis of this qualitative evaluation of the implementation process, we suggest designing relevant incentives to be more equitable and responsive to household size: a fixed amount added to the patient's cash transfer for each member of their household on completion of the condition. In this way, larger households will receive the same amount per household member as smaller households.

\section{Conclusions}

A novel TB-specific socioeconomic intervention was: designed through multi-sectoral collaboration coupled with evidence from a systematic review; refined to meet patient and household needs during implementation through community participation, engagement and acceptability feedback; and proved to be feasible in an impoverished, challenging environment. The intervention is now ready for impact assessment, including by the CRESIPT project. Further lessons from CRESIPT will aim to assist TB control programs to effectively implement the recent global policy change of including socioeconomic support as part of TB control activities.

\section{Additional file}

Additional file 1: Figure S1a. Details of the operational conditions to meet in order to receive double incentives. b: Details of the operational conditions to meet in order to receive simple incentives. (ZIP $492 \mathrm{~kb}$ )

\section{Competing interests}

The authors declare that they have no competing interests.

\section{Authors' contributions}

TW, DB, MT, DH, RM, JL and CAE conceived, designed and refined the study. TW, RM and MT performed data collection and field work in co-ordination with the CRESIPT team (see acknowledgements). TW, MT and CAE analysed the data. TW, DB, MT, DH, RM, JL and CAE all contributed to the writing of the manuscript. All authors read and approved the final manuscript.

\section{Acknowledgements}

The CRESIPT project was funded by the Wellcome Trust, IFHAD and the Joint Global Health Trials Consortium of the Wellcome Trust, UK Medical Research
Council and the Department for International Development (DFID, UK-AID) and the Bill and Melinda Gates Foundation. TW was also supported by the British Infection Association with a research project primer grant. CAE was partially supported by Imperial College Biomedical Research Centre. The funders had no role in study design, data collection and analysis, decision to publish, or preparation of the manuscript.

The authors are grateful to the TB-affected families of Ventanilla and Callao for their participation in the project and invaluable feedback.

The authors are grateful to the IFHAD team for their endless hard work and contributions in the field and laboratory.

\section{Key messages}

1) The World Health Organisation's post-2015 End TB Strategy explicitly identifies social protection and socioeconomic interventions as a key pillar of TB control. However, although cash transfers are an established form of socioeconomic support in HIV and maternal illness, there is minimal operational evidence guiding implementation of TB-specific cash transfers.

2) To inform and assist the wider TB community about the operational logistics of providing TB-specific cash transfers in resource-constrained settings, we designed, implemented and refined a novel TB-specific socioeconomic intervention that included cash transfers aiming to support TB prevention and cure in 32 contiguous shantytowns in Lima, Peru: the Community Randomized Evaluation of a Socioeconomic Intervention to Prevent TB (CRESIPT) project.

3) Nine hundred sixty-four conditional cash transfers (total 20,313 US dollars) were made to 135 recruited TB-affected families. Overall, each family received an average of 173 US dollars over the course of the intervention. Evaluation of acceptability with project participants and key stakeholders described successes and challenges and led to refinement of cash transfer conditionality, size and responsiveness to the needs of TB-affected households.

4) A novel TB-specific socioeconomic intervention proved to be feasible in an impoverished, urban environment and is now ready for impact assessment, including by the CRESIPT project.

\section{Author details}

${ }^{1}$ Innovación Por la Salud Y Desarrollo (IPSYD), Asociación Benéfica PRISMA, Lima, Peru. ${ }^{2}$ Innovation For Health And Development (IFHAD), Infectious Diseases \& Immunity, Imperial College London, and Wellcome Trust Imperial College Centre for Global Health Research, London, UK. ${ }^{3}$ The Monsall Infectious Diseases Unit, North Manchester General Hospital, Manchester, UK. ${ }^{4}$ Department of Infectious Disease Epidemiology, London School of Hygiene \& Tropical Medicine, London, UK. ${ }^{5}$ Innovation For Health And Development (IFHAD), Laboratory of Research and Development, Universidad Peruana Cayetano Heredia, Lima, Peru. ${ }^{6}$ Tulane University School of Public Health and Tropical Medicine, New Orleans, LA, USA. ${ }^{7}$ Johns Hopkins Bloomberg School of Public Health, Baltimore, MD, USA.

Received: 29 December 2014 Accepted: 7 August 2015 Published online: 21 August 2015

\section{References}

1. World Health Organisation. Global report on tuberculosis. 2013. http://apps.who.int/iris/bitstream/10665/91355/1/9789241564656 _eng.pdf?ua=12013. Accessed $11^{\text {th }}$ August 2014.

2. Farmer P. The consumption of the poor. In: Infections and inequalities: the modern plaques. Berkeley and Los Angeles, CA: University of California Press; 2001.

3. Dubos R, Dubos J. The white plague: tuberculosis, man and society. New Brunswick, NJ: Rutgers University Press; 1996. p. xv.

4. Solar O, Irwin A. A conceptual framework for action on the social determinants of health. In: Social determinants of health discussion, Paper 2 (Policy and Practice). Geneva: World Health Organization; 2010.

5. Wingfield T, Schumacher SG, Sandhu G, Tovar MA, Zevallos K, Baldwin MR, et al. The seasonality of tuberculosis, sunlight, vitamin D, and household crowding. J Infect Dis. 2014;210(5):774-83. doi:10.1093/infdis/jiu121. Epub 2014 Mar 4.

6. Wyszewianski L. Households with catastrophic health care expenditures. Health Serv Res. 1986;21:617-34.

7. Wingfield T, Boccia D, Tovar M, Gavino A, Zevallos K, Montoya R, et al. Defining catastrophic costs and comparing their importance for adverse tuberculosis 
outcome with multi-drug resistance: a prospective cohort study, Peru. PLoS Med. 2014;11(7):e1001675. doi:10.1371/journal.pmed.1001675. eCollection 2014.

8. Pronyk P, Lutz B. Policy and programme responses for addressing the structural determinants of HIV, Structural approaches to HIV prevention position paper series. Arlington, VA: USAID's AIDS Support and Technical Assistance Resources, AIDSTAR-One, Task Order 1; 2013. London: UKaid's STRIVE research consortium.

9. Frick M, Jimenez-Levi E. Treatment Action Group (TAG), tuberculosis research and development: 2013 report on tuberculosis research and funding trends, 2005-2012. In: Stop TB Treatment Action Group (TAG). 2013. ISBN \# 978-0-9837221-9-9.

10. Lienhardt C, Ogden JA. Tuberculosis control in resource-poor countries: have we reached the limits of the universal paradigm? Trop Med Int Health. 2004;9:833-41.

11. Garner P, Volmink J. Households help cure tuberculosis. Lancet. 2006;367:878-9.

12. Ogden J, Rangan S, Uplekar M, Porter J, Brugha R, Zwi A, et al. Shifting the paradigm in tuberculosis control: illustrations from India. Int J Tuberc Lung Dis. 1999:3:855-61.

13. Marmot M. Social determinants of health inequalities. Lancet. 2005;365:1099-104.

14. World Health Organization (WHO) Commission on Social Determinants of Health. 2008. Closing the Gap in a Generation: Health Equity through Action on the Social Determinants of Health. Geneva: WHO. and Global Fund to Fight AIDS, Tuberculosis and Malaria (GFATM). The Global Fund's Approach to Health Sytems Strengthening. Geneva: GFATM; 2008.

15. Lonnroth K, Jaramillo E, Williams B, Dye C, Raviglione M. Drivers of tuberculosis epidemics: the role of risk factors and social determinants. Soc Sci Med. 2009;68:2240-6.

16. World Health Organization. 67th World Health Assembly: agenda. In: Documents A67/11 and EB134/2014/REC/1, resolution EB134.R4. 2014. Available: http// apps.who.int/gb/ebwha/pdf_files/WHA67/A67_1Rev1-en.pdf. Accessed on $1^{\text {st }}$ August 2014

17. Tanimura T, Jaramillo E, Weil D, Raviglione M, Lonnroth K. Financial burden for tuberculosis patients in low- and middle-income countries: a systematic review. Eur Resp J. 2014;43:1763-75.

18. United Nations Research Institute for Social Development (UNRISD). Combating poverty and inequality: structural change, social policy and politics. 2010

19. Chatham House. Social protection interventions for Tuberculosis control: the impact, the challenges, and the way forward. In: Meeting summary. London, United Kingdom: Centre for Global Health Security, Chatham House; 2012. Available from: http://www.chathamhouse.org/sites/default/files/public/ Research/Global\%20Health/170212summary.pdf. Accessed 27 $7^{\text {th }}$ July 2014

20. Boccia D, Hargreaves J, Lönnroth K, Jaramillo E, Weiss J, Uplekar M, et al. Cash transfer and microfinance interventions for tuberculosis control: review of the impact evidence and policy implications. Int J Tuberc Lung Dis. 2011;15 Suppl 2:S37-49. doi:10.5588/ijtld.10.0438.

21. Lagarde $\mathrm{M}$, Haines $\mathrm{A}$, Palmer $\mathrm{N}$. The impact of conditional cash transfers on health outcomes and use of health services in low and middle income countries. Cochrane Database Syst Rev. 2009;4, CD008137.

22. World Health Organization. World Health Report. In: Health systems financing: the path to universal coverage. Geneva: World Health Organization; 2010.

23. UNAIDS. UNAIDS expanded business case: enhancing social protection. Geneva: Joint United Nations Programme on HIV/AIDS; 2010.

24. International Labour Organization (ILO). Social protection floor for a fair and inclusive globalization. Geneva: International Labour Organization; 2011.

25. Doetinchem O, Xu K, Carrin G. Conditional cash transfers: what's in it fo health? technical briefing papers, 1. Geneva, Switzerland: World Health Organisation; 2008

26. Pettifor A, MacPhail C, Nguyen N, Rosenberg M. Can money prevent the spread of HIV? A review of cash payments for HIV prevention. AIDS Behav. 2012;16(7):1729-38.

27. Heise L, Lutz B, Ranganathan M, Watts C. Cash transfers for HIV prevention: considering their potential. J Int AIDS Soc. 2013;16(1):18615.

28. Lim SS, Dandona L, Hoisington JA, Spencer L, Hogan MC, Gakidou E. India's Janani Suraksha Yojana, a conditional cash transfer programme to increase births in health facilities: an impact evaluation. Lancet. 2010;375(9730):2009-23.

29. Laxminarayan R, Klein E, Dye C, Floyd K, Darley S, Adeyi O. Economic benefit of tuberculosis control. In: Policy Research Working Paper 4295. WA: The World Bank; 2007.

30. Grede N, Claros JM, de Pee S, Bloem M. Is there a need to mitigate the social and financial consequences of tuberculosis at the individual and household level? AIDS Behav. 2014;18 Suppl 5:S542-53 [Epub ahead of print].
31. Lutge $E$, Wiysonge $C$, Knight $S$, Volmink J. Material incentive and enablers in the management of tuberculosis. Cochrane Database Syst Rev. 2012;1:CD007952.

32. Volmink J, Garner P. Interventions for promoting adherence to tuberculosis management. Cochrane Database Syst Rev. 2000;2:CD000010.

33. Hirsch-Moverman Y, Daftary A, Franks J, Colson P. Adherence to treatment for latent tuberculosis infection: systematic review of studies in the US and Canada. Int J Tuberc Lung Dis. 2008;12:1235-54.

34. Malotte CK, Rhodes F, Mais KE. Tuberculosis screening and compliance with return for skin test reading among active drug users. Am J Public Health. 1998;88:792-6.

35. Malotte CK, Hollingshead JR, Rhodes F. Monetary versus nonmonetary incentives for TB skin test reading among drug users. Am J Prev Med. 1999;16:182-8

36. Pilote L, Tulsky JP, Zolopa AR, Hahn JA, Schecter GF, Moss AR. Tuberculosis prophylaxis in the homeless: a trial to improve adherence to referral. Arch Intern Med. 1996;156:161-5.

37. White MC, Tulsky JP, Reilly P, Mclntosh HW, Hoynes TM, Goldenson J. A clinical trial of a financial incentive to go to the tuberculosis clinic for isoniazid after release from jail. Int J Tuberc Lung Dis. 1998;2:506-12.

38. Craig P, Dieppe P, Macintyre S, Michie S, Nazareth I, Petticrew M. Developing and evaluating complex interventions: new guidance. Br Med J. 2008;337:a1665.

39. Rocha C, Montoya R, Zevallos K, Curatola A, Ynga W, Franco J, et al. The Innovative Socio-economic Interventions Against Tuberculosis (ISIAT) project: an operational assessment. Int J Tuberc Lung Dis. 2011;15(2):S50-7. doi:10.5588/ijtld.10.0447.

40. Adato M. Social protection: opportunity for Africa. Washington DC, USA: International Food Policy Research Institute policy brief; 2008.

41. Lutge E, Lewin S, Volmink J, Friedman I, Lombard C. Economic support to improve tuberculosis treatment outcomes in South Africa: a pragmatic cluster-randomized controlled trial. Trials. 2013;14:154.

42. Kim J, Ferrari G, Abramsky T, Watts C, Hargreaves J, Morison L, et al. Assessing the incremental effects of combining economic and health interventions: the IMAGE study in South Africa. Bull World Health Organ. 2009;87(11):824-32

43. Richter LM, Lönnroth K, Desmond C, Jackson R, Jaramillo E, Weil D. Economic support to patients in HIV and TB grants in rounds 7 and 10 from the global fund to fight AIDS, tuberculosis and malaria. PLoS One. 2014 Jan 28;9(1):e86225. doi:10.1371/journal.pone.0086225. eCollection 2014.

44. Subbaro K, Bonnerjee A, Braithwaite J, Carvalho S, Ezemenan K. Safety net programs and poverty reduction: Lessons from cross-country experience. Washington, DC: World Bank; 1997.

45. Sripad A, Castedo J, Danford N, Zaha R, Freile C. Effects of Ecuador's national monetary incentive program on adherence to treatment for drug-resistant tuberculosis. Int J Tuberc Lung Dis. 2014;18(1):44-8. doi:10.5588/ijtld.13.0253.

46. Adato $M$, Bassett $L$. What is the potential of cash transfers to strengthen households affected by HIV and AIDS? A review of the evidence on impacts and key policy debate, Joint learning initiative on children and HIV/AIDS JLICA. Washington, DC, United States: Food Consumption and Nutrution Division. International Food Policy Research Institute; 2008.

47. Fiszbein A, Schady N, Ferreira FHG, Grosh M, Kelleher N, Olinto P. Conditional cash transfers: reducing present and future poverty. Washington D.C: The World Bank; 2009.

48. Barrientos A, DeJong J. Reducing child poverty with cash transfers: a sure thing? Dev Policy Rev. 2006;24(5):537e552.

49. Fernald L, Hidrobo M. Effect of Ecuador's cash transfer program (Bono de Desarrollo Humano) on child development in infants and toddlers: a randomized effectiveness trial. Soc Sci Med. 2011;72:1437-46.

50. Thim S, Sath S, Sina M, Tsai EY, Delgado JC, Shapiro AE. A community-based tuberculosis program in Cambodia. JAMA. 2004;292(5):566-8.

51. Robertson L, Mushati P, Eaton JW, Dumba L, Mavise G, Makoni J, et al. Effects of unconditional and conditional cash transfers on child health and development in Zimbabwe: a cluster-randomised trial. Lancet. 2013;381(9874):1283-92.

52. WHO TB profile of Peru 2012. Accessed $30^{\text {th }}$ August 2014. https:// extranet.who.int/sree/Reports?op=Replet\&name=/WHO_HQ_Reports/G2/ PROD/EXT/TBCountryProfile\&ISO2=PE\&outtype $=$ html.

53. Herlihy N, Wingfield T, Rivero M, Tovar M, Montoya R, Carlton Evans. Tuberculosis programs incorporating mobile phones as tools may overlook the most vulnerable TB patients in low-resource countries. In: Poster presentation PC-382-01, Session 9: information technology to improve TB control. Paris: 44th Union World Conference in Lung Health; 2013. 
54. Floyd K. Costs and effectiveness - the impact of economic studies on TB control. Tuberculosis. 2003;83:187-200.

55. Floyd K, Pantoja A. Financial resources required for tuberculosis control to achieve global targets set for 2015. Bull World Health Organ. 2008;86:568-76.

56. Laokri S, Drabo MK, Weil O, Kafando B, Dembélé SM, Dujardin B. Patients are paying too much for tuberculosis: a direct cost-burden evaluation in Burkina Faso. PLoS One. 2013;8(2):e56752. doi:10.1371/journal.pone.0056752. Epub 2013 Feb 25.

57. Ukwaja KN, Alobu I, Abimbola S, Hopewell PC. Household catastrophic payments for tuberculosis care in Nigeria: incidence, determinants, and policy implications for universal health coverage. Infect Dis Poverty. 2013;2(1):21.

58. Diagnóstico Socio Económico Laboral de la Región Callao 2012 http://www.mintra.gob.pe/archivos/file/estadisticas/peel/osel/2012/Callao/ Estudio/Estudio_012012_OSEL_Callao.pdf. Ministerio de Trabajo y Promocion del empleo de Peru.

59. Wingfield T, Tovar M, Montoya R, Huff D, Lewis JJ, Evans CA. The CRESIPT project: community feedback and practical challenges of conditional cash transfers for TB-affected households in Peru. In: Oral abstract presentation during Symposium 50, Enhancing TB control with structural interventions: from incentives and enablers to social protection. Barcelona: 45th Union World Conference in Lung Health; 2014.

60. Samson M, Niekerk IV, Mac K. Designing and implementing social transfer programmes. 2nd ed. Cape Town: Economic Policy Research Institute; 2006.

61. Aker J, Boumnijel R, McClelland A, Tierney N. "Zap It to Me: The Short-Term Impacts of a Mobile Cash Transfer Program". In: CGD Working Paper 268. Washington, D.C: Center for Global Development; 2011. http://www.cgdev.org/ content/publications/detail/1425470.

62. Sherr L, Rodgers A, Varrall R, Mueller J, Adato M. Examining ways in which contact opportunities associated with transfers might help identify vulnerable households and link them with social welfare services: a systematic review of the literature. Vulnerable Children Youth Stud. 2009;4(S1):10e40.

63. Leatherman L. A biocultural perspective on health and household economy in Southern Peru. Med Anthropol Q. 1996;10(4):476-95.

\section{Submit your next manuscript to BioMed Central and take full advantage of:}

- Convenient online submission

- Thorough peer review

- No space constraints or color figure charges

- Immediate publication on acceptance

- Inclusion in PubMed, CAS, Scopus and Google Scholar

- Research which is freely available for redistribution 